\title{
WestVirginiaUniversity.
}

Department of Economics

Working Paper Series

\section{Outcome Uncertainty, Fan Travel, and Aggregate Attendance}

Brad R. Humphreys

Thomas J. Miceli

Working Paper No. 16-26

This paper can be found at the College of Business and Economics Working Paper Series homepage: 


\title{
Outcome Uncertainty, Fan Travel, and Aggregate Attendance
}

\author{
Brad R. Humphreys \\ West Virginia University \\ Thomas J. Miceli \\ University of Connecticut
}

20 December 2016

\begin{abstract}
The classical Uncertainty of Outcome Hypothesis (UOH) informs economists' understanding consumer decisions to attend sporting events and models of team revenue generation. Coates, Humphreys and Zhou (2014) developed a reference dependent preference based consumer choice model under uncertainty to motivate the $\mathrm{UOH}$ in which loss-averse consumers prefer games with certain outcomes. We develop an alternative model based on a standard expected utility model of fan behavior which incorporates fans' decisions to travel to away games and aggregates decisions across local and visiting fans. This model generates predictions consistent with the classical $\mathrm{UOH}$ and concave team and league-wide total revenue functions.
\end{abstract}

Keywords: outcome uncertainty, game attendance, aggregation, travel

JEL Codes: L83, D12, Z20

Humphreys: Department of Economics, West Virginia University, PO Box 6025, Morgantown, WV 26506. Email: brhumphreys@mail.wvu.edu; Phone: 304-293-7871; Fax: (304) 293-2233.

Miceli: Department of Economics, University of Connecticut, 309 Oak Hall, 365 Fairfield Way Storrs, CT 06269-1063. Email: Thomas.Miceli@UConn.edu; Phone: (860) 486-5810; Fax: (860) 486-4463 


\section{Introduction}

The uncertainty of outcome hypothesis (UOH) represents a key concept in sports economics. Rottenberg (1956), in a seminal paper, observed that attendance tends to increase at games or matches with uncertain outcomes, and decline at those with more certain outcomes, including when the home team is thought to be very likely to win: "the 'tighter' the competition, the larger the attendance. A pennant winning team that wins 80 percent of its games will attract fewer patrons than a pennant-winning team that wins 55 per cent of its games. (page 246, footnote 21)”. This statement contains a clear prediction about the relationship between game attendance and consumers' expectations of game outcomes.

Outcome uncertainty can be applied to game outcomes, season outcomes, or postseason (championship) outcomes (Szymanski, 2003). In each case, consumers of a specific good, live sporting contests, make decisions about consuming the good when the actual consumption experience, the game, season-long, or postseason contest, has an uncertain component. Rottenberg's observation generated an extensive empirical literature. Game and total season attendance data are readily available for many sporting events, and proxies for game or season uncertainty can be imputed from betting market data or from past team performance.

The UOH was also incorporated into models of team and league behavior. El Hodiri and Quirk (1971) remarked: "The essential economic fact concerning professional team sports is that gate receipts depend crucially on the uncertainty of outcome of the games played within the league. As the probability of either team winning approaches 1, gate receipts fall substantially" when motivating their assumption that team gate revenue is a concave function of the probability that a team wins a game or match. Fort and Quirk (1995) make a similar assumption motivated by a similar argument. Vrooman (1995) assumes marginal gate and broadcast revenue are a nonincreasing function of team strength (and implicitly, of the probability the home team wins a game) with no supporting argument; by the time these latter papers were published, the UOH was fully incorporated into models of team and league behavior.

Despite this widespread adoption of the $\mathrm{UOH}$, economists paid little attention to the theoretical basis of this "essential economic fact," which is clearly rooted in consumer decision making under uncertainty. Coates, Humphreys and Zhou (2014) recently developed a reference dependent preference (RDP) based model of consumers' decisions to attend sporting events. In this model consumers compare the expected utility of attending a game with an uncertain outcome to a level of reservation utility and attend if expected utility exceeds reservation utility. The RDP model generates predictions consistent with the $\mathrm{UOH}$ under certain assumptions about the relative importance of loss aversion, but also generates predictions that consumers prefer to attend games with low expected home win probability -- a preference for upsets -- and also prefer to attend games with high expected home win probability -- home win preference -- if loss aversion is sufficiently strong. ${ }^{1}$ The model also requires RDPs to generate predictions consistent with the $\mathrm{UOH}$; removing RDPs from the model generates only consumer home win preference, where expected utility and attendance strictly increases with expected home win probability.

\footnotetext{
${ }^{1}$ Keefer (2015) developed a similar model that also requires fans have reference dependent preferences.
} 
In addition to the importance of RDPs, the loss aversion form of the Coates, Humphreys and Zhou (2014) model cannot be easily reconciled with the standard aggregate team revenue functions embedded in the league models developed by El Hodiri and Quirk (1971), Fort and Quirk (1995) and Vrooman (1995). If expected consumer utility is a convex function of expected home win probability, then the relationship between total gate revenues earned by a team over the course of a season and the expected probability that the team wins each of the home games played over the course of a season is a complex function of the talent choice of the team and the talent choice made by other teams in the league. Under the $\mathrm{UOH}$, expected utility is a concave function of the expected probability that a team wins each game during the season, and total gate revenues will clearly be a concave function of team talent choice.

In this paper, we develop a model of consumer attendance choice under uncertainty based on standard Friedman-Savage expected utility (Friedman and Savage, 1948). The model includes direct costs of attendance and travel costs, and includes attendance by both local fans and fans of the visiting team. The model generates attendance-home win probability predictions consistent with the UOH because of the possibility that visiting fans will attend games. By focusing on choices made by both local fans and visiting fans, the model generates predictions that attendance will be higher at games with an uncertain outcome without additional assumptions about reference dependence of fan preferences. The inclusion of fan heterogeneity rather than a representative fan also generates aggregate team revenue functions consistent with those in the league models developed by El Hodiri and Quirk (1971), Fort and Quirk (1995) and Vrooman (1995).

\section{The Model}

We develop a basic model of consumer preferences over sporting events that forms the basis for a derivation of an expression for total team attendance. We adopt a simple setup in which consumers are risk-neutral and seek to maximize a standard Friedman-Savage expected utility function of the form

$$
E[U]=p U^{W}+(1-p) U^{L},
$$

where $p$ is the probability of a win by the home team, $U^{W}$ is the utility from a home team win, and $U^{L}$ is the utility from a home team loss. This utility function is identical to the expected utility function with no reference dependent preferences in Coates, et al (2014).

We assume that $U^{W}>U^{L} \geq 0$, reflecting the higher utility from a home-team win versus a loss. For simplicity, we set $U^{L}=0$ in what follows, though this normalization is for convenience and all predictions would be identical under the assumption that $U^{L}>0$. Game attendance clearly yields entertainment benefits to some consumers apart from the outcome of the contest. Under this simplifying assumption, Equation (1) becomes $E[U]=p U^{W}$.

To translate individual fan preferences into aggregate attendance, let $U^{W}$ be a random variable that is distributed across fans according to the distribution function $F\left(U^{W}\right)$, where variation in $U^{W}$ reflects differing degrees of loyalty across the fan base. 
Home-team fans decide whether or not to attend a game by comparing the expected utility from attendance to the utility from their next-best option, denoted $v$, which can be interpreted as home fans' opportunity cost associated with game attendance. $v$ reflects the presence of alternative entertainment activities in the city, factors under the team's control like ticket prices, parking and concession prices, as well as travel costs to the game. For simplicity we assume that this opportunity cost is identical for all potential attendees. We also assume that $v$ does not vary systematically with the probability that the home team will win a game. Only home-team fans for whom $E[U] \geq v$ will chose to attend games. Total attendance by home-team fans can therefore be computed as

$$
A_{h}=\operatorname{Pr}\left(p U^{W} \geq v\right)=\operatorname{Pr}\left(U^{W} \geq v / p\right)=1-F(v / p) .
$$

It follows that attendance is strictly increasing in $p$, the probability of team victory. Although this is an intuitively appealing result, if it were the only factor driving overall game attendance, it would not be consistent with the $\mathrm{UOH}$, since more fans would attend games with certain outcomes, where $p$ is large, than would attend games with uncertain outcomes, where $p$ is near 0.5. Attendance would be strictly higher at games the home team is expected to win. Also, note that as ticket prices go up, $v$ increases, and attendance falls, holding other factors constant.

Next, we extend the model to allow for attendance by fans of the visiting team. These fans could alternatively be thought of as any fan unattached to the home team, or people with different preferences than home team fans. In contrast to the above specification, the probability of a victory from the perspective of visiting team fans is $1-p$. We also allow for a different distribution of $U^{W}$ for visiting team fans, denoted $G\left(U^{W}\right)$, since fans who travel to away games may differ systematically from fans who only attend home games. Otherwise, the approach is the same as above. Total visiting fan attendance can be written

$$
A_{v}=\theta[1-G(v /(1-p))],
$$

where $\theta \leq 1$ is a weighting factor that reflects the cost of traveling from the visiting team's city to the home team's city. $\theta$ varies inversely with the distance between the cities, along with other team-specific factors like access to the facility, ease of obtaining tickets on primary or secondary ticket markets, attractiveness of the host city as a tourist destination, and other attendance-related and travel-related factors.

Total attendance at a game is given by

$$
\begin{aligned}
A & =A_{h}+A_{v} \\
& =1-F(v / p)+\theta[1-G(v /(1-p))] .
\end{aligned}
$$

From Equation (4), total attendance varies ambiguously with $p$-a larger probability of home-team victory increases attendance by fans of the home team but reduces attendance by fans of the visiting team. To arrive at a more specific prediction, we assume that both $F(\cdot)$ and $G(\cdot)$ are uniform on $[0, \bar{U}]$, in which case Equation (4) becomes 


$$
A=\left(1-\frac{v}{p \bar{U}}\right)+\theta\left(1-\frac{v}{(1-p) \bar{U}}\right)
$$

The key issue is the determination of the attendance maximizing expected home win probability. Maximizing Equation (5) with respect to $p$ yields ${ }^{2}$

$$
p^{*}=\frac{1}{1+\theta^{1 / 2}}
$$

which is a modified version of the $\mathrm{UOH}$, where $p^{*} \geq 1 / 2$ as $\theta \leq 1$. Thus, the closer geographically are the two cities, the nearer is $p^{*}$ to fifty percent.

The reason the current model, which depends only on expected utility, is consistent with the UOH is that it does not require a "representative fan's" utility to be maximized at an expected home team win probability of fifty percent, which appears to be consistent with the conventional approach in the UOH literature. Rather, it only requires that the aggregation of fan utilities (including that of visiting-team fans) be maximized at home team expected win probabilities of (approximately) fifty percent. Individual fan utility can be maximized at high levels of expected home win probabilities, since attendance at games depends on choices made by both local and outof-town fans.

Equation (6) generates testable predictions. Teams in leagues with relatively long schedules like MLB, the NBA and the NHL play each other multiple times in each season, especially divisional rivals, which are generally located close to each other. Equation (6) implies that, over long periods of time, the probability that one home team beats another visiting team should vary systematically with the distance between the two cities, holding other factors like relative team quality constant. This prediction is testable using the same data used to test for evidence of the UOH.

\section{Implications for Aggregate Revenue Functions}

One key feature of models of consumer game attendance choice, or live television viewing of individual games or matches, is the relationship between individual consumer decisions and total team revenue over a season, or a number of seasons. In the team and league models developed by El Hodiri and Quirk (1971), Fort and Quirk (1995) and Vrooman (1995), teams choose profit maximizing levels of talent given their own market decisions and the talent choices made by other teams under an adding-up restriction on wins in the league.

El Hodiri and Quirk (1971) generate team-level revenue functions based on the probability that a given home team wins a game by assumption. El Hodiri and Quirk (1971) posit that total season revenues earned by team $i$ is an additive function of the revenues earned in games between team $i$ and team $j\left[R_{i j}(i)\right]$; this function is assumed to be a concave function of the probability that team $i$ will defeat team $j$ in a given game, $P^{i j}$.

\footnotetext{
${ }^{2}$ It can be verified that $\partial^{2} A / \partial p^{2}<0$, so this is indeed a maximum.
} 
Fort and Quirk (1995) take a more general approach by defining a function $Z^{i j}(t)=w^{i}(\mathrm{t})-w^{j}(\mathrm{t})$ where $w^{i}(\mathrm{t})$ and $w^{j}(\mathrm{t})$ are the profit maximizing talent choices of teams $i$ and $j$ respectively. Fort and Quirk (1995) assume that total revenue generated in each game is a function of $Z^{i j}(t)$ that is maximized when $Z^{i j}(t)$ is near zero.

In both cases, the team's total revenue function can be obtained by adding up the total revenues generated from individual games, because individual game revenues are concave functions of the probability that the home team wins each game with a unique maximum somewhere near a value of 0.5 . Concavity of this relationship ensures that total team revenues will be higher for both teams when the expected probability of a home team win is near 0.5 . When teams' profit maximizing talent choices diverge, and one team chooses to hire more playing talent and win more games than the other, the weaker team loses revenues because its fans get less utility from attending games where the expected home team winning percentage is low, and fewer attend these games. The stronger team loses revenues because its fans get less utility from attending games where the expected home win probability is high, and fewer attend these games.

The loss aversion form of the model developed by Coates, Humphreys and Zhou (2014) makes this aggregation approach to defining total team revenue functions problematic, because the expected utility function for an individual representative fan is convex in the expected probability of a home win. When both teams choose relatively equal amounts of talent, games will have uncertain outcomes, and some loss averse fans will choose not to attend these games in both cities. In this form of the model, both teams' revenues increase when the teams choose differing levels of talent. Games hosted by the stronger team have higher attendance than games with uncertain outcomes because of local fan's home win preference. Games hosted by the weaker team have higher attendance because of local fan's upset preference.

Under strict home win preference -- the version of the model developed by Coates, Humphreys and Zhou (2014) with no reference dependent preferences -- total team revenues increase when the two teams choose different levels of talent. The more talented team sees increases in revenues and typically draws larger crowds, while the less talented team sees decreases in revenues and draws smaller crowds. The more talented team plays in a market where the MR of a win is larger, so the increase in a strong team's revenues should exceed the decrease in a weak team's revenues.

The model developed here avoids this problem by relaxing the assumption of a representative (local) fan. Instead, this model includes heterogeneous attendees: local fans with preferences for seeing their team win, and out-of-town fans with who prefer to see their team win and increasingly choose to attend away games when their team gets stronger. In addition, the aggregate revenue functions used in standard models of league play emerge naturally from the current model.

\section{Conclusions}

The Uncertainty of Outcome Hypothesis has been a central feature of economic models of attendance at sporting contests dating back to the seminal analysis by Rottenberg (1956). According to this hypothesis, fans prefer to attend games in which the outcome is uncertain - that is, the contest itself, independently of fan loyalty to a particular team, is a component of 
preferences. Although this hypothesis has formed the basis of the large and growing literature on sports economics, there is little theoretical foundation for it. A recent paper by Coates, Humphreys, and Zhou (2014) offered an explanation that relied on reference-dependent preferences and loss aversion, but the resulting model is not consistent with standard aggregate models of team behavior that for decades have been the basis for empirical analyses of sports leagues.

The contribution here is to develop a consumer choice model based on standard neo-classical consumer theory that is also compatible with existing models of aggregate league outcomes (El Hodiri and Quirk, 1971; Fort and Quirk, 1995; Vrooman; 1995). The key insight is to move away from a "representative fan" approach to modeling consumer behavior and instead to consider the aggregated preferences of both home and visiting fans for a particular contest. This approach naturally generates a modified version of the $\mathrm{UOH}$ (one that accounts for the travel costs of visiting fans) because of the competing interests and heterogeneous fan preferences for wins. The analysis provides a parsimonious explanation for the $\mathrm{UOH}$ that is both grounded in neo-classical consumer behavior and is consistent with team-level revenue functions. It thus provides a firm theoretical basis for this critical component of models of league outcomes. 


\section{References}

Coates, D., Humphreys, B. R., \& Zhou, L. (2014). Reference-Dependent Preferences, Loss Aversion, and Live Game Attendance. Economic Inquiry, 52(3), 959-973.

El-Hodiri, M., \& Quirk, J. (1971). An Economic Model of a Professional Sports League. Journal of Political Economy, 79(6), 1302-1319.

Fort, R., \& Quirk, J. (1995). Cross-Subsidization, Incentives, and Outcomes in Professional Team Sports Leagues. Journal of Economic Literature, 33(3), 1265-1299.

Friedman, M., \& Savage, L. (1948). The Utility Analysis of Choices Involving Risk. Journal of Political Economy, 56(4), 279-304.

Keefer, Q. A. W. (2015). Why Do People Support the Underdog?: Loss Aversion and Sports Fans. International Journal of Applied Behavioral Economics, 4(4), 17-35.

Rottenberg, S. (1956). The Baseball Players' Labor Market. Journal of Political Economy, 64(3), 242-258.

Szymanski, S. (2003). The Economic Design of Sporting Contests. Journal of Economic Literature, 41(4), 1137-1187.

Vrooman, J. (1995). A General Theory of Professional Sports Leagues. Southern Economic Journal, 61(4), 971-990. 